\title{
Rational in silico design of novel $\alpha$-glucosidase inhibitory peptides and in vitro evaluation of promising candidates
}

\author{
Mohammed Auwal Ibrahim ${ }^{\mathrm{a}, \mathrm{c}^{*}}$, Megan J. Bester ${ }^{\mathrm{b}}$, Albert W. Neitz ${ }^{\mathrm{a}}$ and \\ Anabella R. M. Gaspar ${ }^{a}$ \\ ${ }^{a}$ Department of Biochemistry, University of Pretoria, Pretoria 0002, South Africa \\ ${ }^{b}$ Department of Anatomy, University of Pretoria, Pretoria 002, South Africa \\ ${ }^{c}$ Department of Biochemistry, Ahmadu Bello University, Zaria, Nigeria
}

\section{Highlights}

- 4210 peptides were designed and subjected to in silico simulated GIT digestion.

- 844 GIT resistant peptides were subjected to molecular docking on $\alpha$-glucosidase.

- SVPA and SEPA had the lowest binding free energy against $\alpha$-glucosidase.

- In vitro SVPA and SEPA inhibited both $\alpha$-glucosidase and $\alpha$-amylase.

- SEPA has potential as a novel $\alpha$-glucosidase $\underline{\text { inhibitory peptide for treating diabetes. }}$

*Correspondence to: Dr. Mohammed Auwal Ibrahim, Department of Biochemistry, Faculty of Natural and Agricultural Sciences, University of Pretoria, Pretoria 0002, South Africa E mail: mauwalibrahim@gmail.com or maibrahim@abu.edu.ng 


\section{Graphical abstract}

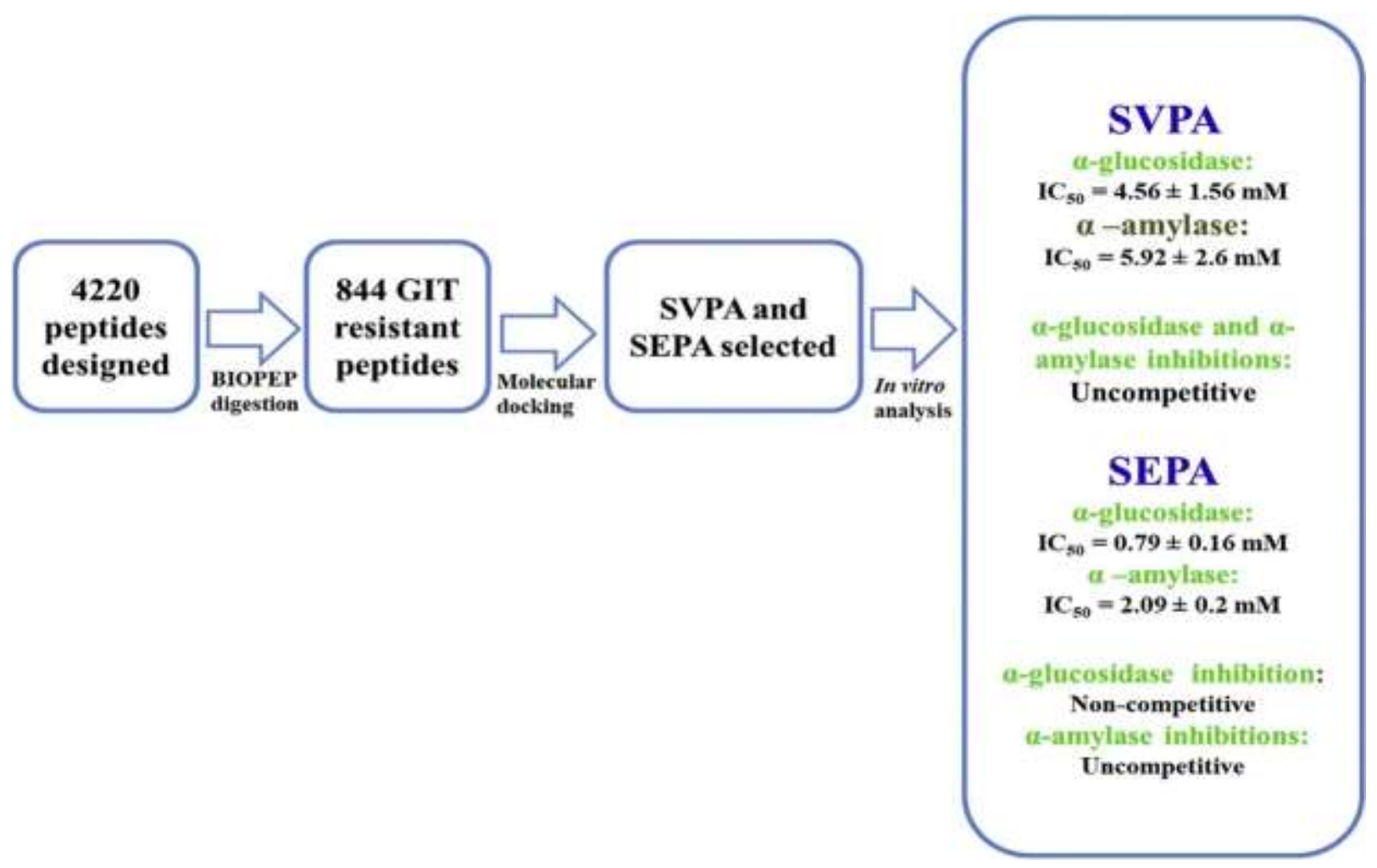

\section{ABSTRACT}

Treatment of type 2 diabetes is achieved through the inhibition of carbohydrate hydrolyzing enzymes such as $\alpha$-glucosidase and $\alpha$-amylase. The present study was conducted to identify novel $\alpha$-glucosidase inhibitory peptides and to validate the $\alpha$-glucosidase and $\alpha$-amylase inhibitory activities of two promising candidates. A total of 4210 potential $\alpha$-glucosidase inhibitory peptides with 3-5 amino acid residues were designed and individually subjected to in silico simulated gastrointestinal (GIT) digestion using the BIOPEP database. Subsequently, 844 GIT resistant peptides were then subjected to molecular docking using Autodock Vina to determine their binding free energy against human $\alpha$-glucosidase (PDB ID: 3L4Y). Among all the peptides, SVPA and SEPA were found to have the lowest binding free energies of -8.7 and $8.6 \mathrm{kcal} / \mathrm{mol}$, respectively. Docking of SVPA and SEPA on human $\alpha$-amylase (PDB ID, 4GQR) identified that both peptides also bind to $\alpha$-amylase with binding energies of -6.5 and -6.9 $\mathrm{kcal} / \mathrm{mol}$, respectively. Hydrogen bond interactions were critical for the binding of both peptides to the $\alpha$-glucosidase and $\alpha$-amylase. In vitro, SVPA and SEPA inhibited $\alpha$-glucosidase and $\alpha$ amylase activities with $\mathrm{IC}_{50}$ values several fold lower than acarbose except for SVPA that had a 
significantly higher $(p<0.05) \mathrm{IC}_{50}$ value than acarbose against $\alpha$-glucosidase. Lineweaver-Burk analyses revealed that SVPA was an uncompetitive inhibitor of the two enzymes, while SEPA inhibited $\alpha$-glucosidase and $\alpha$-amylase non-competitively and uncompetitively, respectively. This study has identified two novel and active $\alpha$-glucosidase inhibitory peptides that could resist GIT digestion and therefore, have the potential to retard postprandial hyperglycemia in diabetic patients.

Keywords: Bioactive peptides; Diabetes mellitus; $\alpha$-glucosidase inhibitors; gastrointestinal digestion; In silico analysis; molecular docking;

\section{Introduction}

According to the World Health Organization, diabetes mellitus is the $7^{\text {th }}$ leading cause of death affecting about 415 million people worldwide and the number is estimated to increase to 642 million by 2040 [1, 2]. Diabetes mellitus is a metabolic disorder characterized by defects in insulin secretion and/or action leading to chronic hyperglycemia as well as alterations in carbohydrate, lipid and protein metabolism in addition to severe micro- and macro-vascular complications [3]. Diabetes mellitus is broadly classified into type 1 (T1D) and type 2 diabetes (T2D) where the latter accounts for more than $90 \%$ of total diabetes cases worldwide. Therefore, effective therapeutic strategies against T2D are important priorities for public health agencies, the pharmaceutical industry and the scientific community.

Currently, there are different classes of hypoglycemic agents used for T2D management and among them, are the $\alpha$-glucosidase inhibitors [4]. This class of drugs inhibits carbohydrate digestion by targeting the enzymes; $\alpha$-amylase and $\alpha$-glucosidase, thereby reducing postprandial hyperglycemia by delaying hydrolysis of starch and other complex carbohydrates. $\alpha$-Amylase ( $\alpha$ 1,4-glucan-4-glucanohydrolase, E.C. 3.2.1.1) catalyses the initial step of starch hydrolysis to maltose, while $\alpha$-glucosidase, a membrane-bound enzyme in the epithelial mucosa of the small intestine, catalyses the hydrolysis of maltose and other disaccharides to release free glucose molecules $[5,6]$. Thus, inhibitors targeting these enzymes ultimately impede the uptake of glucose from complex dietary carbohydrates into the blood circulation, thereby effectively diminishing postprandial hyperglycemia. However, the clinically available $\alpha$-glucosidase and $\alpha$ - 
amylase inhibitors, such as acarbose, are associated with multiple gastrointestinal (GIT) side effects such as flatulence (78\% of patients) and diarrhea (14\% of patients) [7]. Furthermore, the synthesis of these inhibitors is difficult because of their characteristic sugar mimetic structure [8]. Therefore, there is a need to use novel strategies to develop new drugs that are better tolerated and are simpler to synthesize.

In the last decade, research interest in bioactive peptides and protein hydrolysates with $\alpha$ glucosidase inhibitory activity has increased and is attracting the attention of food and biopharmaceutical industries [9]. This is due to the high specificity and affinity as well as low immunogenicity and toxicity profiles of these peptides and hydrolysates [11]. In our previous study, we observed that, so far, a total of 43 fully sequenced peptides have been investigated for $\alpha$-glucosidase inhibitory activity and the findings were highly varied [11]. Based on the results of these studies, we identified the structural properties required for the rational design of novel $\alpha$ glucosidase inhibitory peptides [11].

In the present study, the previously identified structural properties were used to design a library of 4210 peptides containing 3-5 amino acid residues, with potential $\alpha$-glucosidase inhibitory activity. For in vitro evaluation, it was necessary to identify the best candidates and only peptides with predicted in silico GIT stability and low binding free energies for $\alpha$ glucosidase were selected. Subsequently, SVPA and SEPA, two promising peptides were identified and further evaluated for in vitro $\alpha$-glucosidase and $\alpha$-amylase inhibitory activities followed by inhibition kinetic analyses.

\section{Materials and methods}

\subsection{Chemicals and reagents}

Yeast $\alpha$-glucosidase, porcine pancreatic amylase, p-nitrophenyl- $\alpha$-D-glucopyranoside (pNPG), starch, maltose, dinitrosalicylic acid (DNS) and acarbose were obtained from SigmaAldrich (Johannesburg, South Africa). Peptides, SVPA and SEPA were synthesized using Flexpeptide $^{\mathrm{TM}}$ technology by GenScript (New Jersey, USA). The purity, molecular mass and amino acid analysis of the peptides were determined by the manufacturer. 


\subsection{Construction of a library of possible $\alpha$-glucosidase inhibitory peptides}

Previously, we analyzed 43 fully sequenced $\alpha$-glucosidase inhibitory peptides reported in the literature and identified the structural requirements for the design of novel and highly active $\alpha$-glucosidase inhibitory peptides [11]. This includes the presence of amino acids containing a hydroxyl or basic side chain at the $\mathrm{N}$-terminal, proline preferably at the penultimate $\mathrm{C}$-terminal position and alanine or methionine at the C-terminal end. Therefore, in this study, peptide sequences with 3-5 amino acid residues were designed with serine, threonine, tyrosine, lysine or arginine as the ultimate $\mathrm{N}$-terminal residue, proline at the penultimate $\mathrm{C}$-terminal position and alanine or methionine at the ultimate $\mathrm{C}$-terminal position [11]. For peptide sequences with 4 and 5 amino acid residues, the remaining positions were substituted with each of the 20 standard amino acids. Details of the combination strategy for the design of the peptide library are provided in Table 1.

Table 1. Combination strategy for the design of a library of $\alpha$-glucosidase inhibitory peptides

\begin{tabular}{llll}
\hline Serial number & Tripeptides & Tetrapeptides & Pentapeptides \\
\hline 1 & SPA & SXPA & SXXPA \\
2 & SPM & SXPM & SXXPM \\
3 & TPA & TXPA & TXXPA \\
4 & TPM & TXPM & TXXPM \\
5 & YPA & YXPA & YXXPA \\
6 & YPM & YXPM & YXXPM \\
7 & KPA & KXPA & KXXPA \\
8 & KPM & KXPM & KXXPM \\
9 & RPA & RXPA & RXXPA \\
10 & RPM & RXPM & RXXPM \\
Total & $\mathbf{1 0}$ & $\mathbf{2 0 0}$ & $\mathbf{4 0 0 0}$ \\
\hline
\end{tabular}

The peptide library was based on the postulation by Ibrahim et al. [11]. X represents all the 20 standard amino acid residues which were substituted in all cases to obtain the total sum of 4210 peptides

\subsection{In silico simulated gastrointestinal digestion of the designed peptides}

In silico analysis to determine the potential survival of the designed peptides in an in vivo environment was performed. All the designed peptide sequences were assessed for potential 
hydrolysis by the GIT digestion enzymes using the BIOPEP database (http://www.uwm.edu.pl/biochemia/index.php/en/biopep). To mimic the in vivo digestion, the "Enzyme(s) action" application in the BIOPEP database was used to simultaneously digest each of the peptides by using a combination of digestive enzymes in the GIT; pepsin ( $\mathrm{pH} 1.3$ ), chymotrypsin (EC 3.4.21.1) and trypsin (EC 3.4.21.4).

\subsection{Molecular docking studies}

Peptides that were resistant to in silico simulated GIT digestion were selected for molecular docking to determine their binding free energies toward $\alpha$-glucosidase, while peptides that were hydrolyzed during the simulated GIT digestion were excluded from further studies. To perform the molecular docking analysis, the 3D crystal structure of the $\mathrm{N}$-terminal of human intestinal $\alpha$-glucosidase (PDB ID 3L4Y resolved to $1.80 \AA$ by $\mathrm{x}$-ray diffraction) was retrieved in PDB format from the protein data bank (www.rcsb.org). Subsequently, chimera version 1.11.2 (www.cgl.ucsf.edu/chimera/) was used to remove the co-crystallized ligand and water molecules from the protein structure. Thereafter, the dock prep tool of the chimera software was used to prepare the protein for docking. All default parameters for the dock prep tool in chimera were used. The PDB prepared versions of the protein and the peptide ligands were opened in chimera and subjected to the Autodock Vina tool [12] in the same software. The grid sizes (xyz points) were set as 59.7813, 57.7237 and 53.9168, while the grid centers were designated at dimensions (x, y and z) 10.4828, -7.0484 and -19.7638. Other parameters of Autodock Vina in chimera were left as default. AutoDock Vina employs iterated local search global optimizer and all output files were saved in pdbqt format. After the successful docking, the minimum binding free energy for each of the peptides was recorded, while for the two peptides with the lowest binding free energy, the docking pose was extracted and aligned with the receptor structure for further analysis of hydrogen bond interactions. Furthermore, the two selected peptides were subjected to the same molecular docking on human pancreatic $\alpha$-amylase (PDB ID, 4GQR, resolved to $1.20 \AA$ by x-ray diffraction) and similar docking procedures were followed as described for $\alpha$ glucosidase above except that in the case of human $\alpha$-amylase, the grid sizes (xyz points) were set as $41.4677,45.3564$ and 347.2430, while the grid centers were designated at dimensions (x, y and z) $9.3853,43.4138$ and 214.675 . 


\subsection{Assay for $\alpha$-glucosidase inhibitory activity of the peptides}

The $\alpha$-glucosidase inhibitory activity was assayed according to a previously described method [13] with slight modifications. Briefly, $50 \mu \mathrm{L}$ of each peptide or acarbose at a final concentration range of $15.63-500 \mu \mathrm{M}$ was incubated with $25 \mu \mathrm{L}$ of $0.5 \mathrm{U} / \mathrm{mL} \alpha$-glucosidase solution in $100 \mathrm{mM}$ sodium phosphate buffer ( $\mathrm{pH}$ 6.8) at $37{ }^{\circ} \mathrm{C}$ for $60 \mathrm{~min}$. Thereafter, $25 \mu \mathrm{L}$ of pNPG solution (5 mM) in $100 \mathrm{mM}$ sodium phosphate buffer ( $\mathrm{pH} 6.8$ ) was added and the mixture was further incubated at $37^{\circ} \mathrm{C}$ for $30 \mathrm{~min}$. The absorbance of the released $p$-nitrophenol was measured at $405 \mathrm{~nm}$ using a Spectramax paradigm multi-mode microplate reader (Molecular Devices LLC, USA) and the inhibitory activity was expressed as percentage of a control sample without the inhibitors. The $\alpha$-glucosidase inhibitory activity of the peptides was calculated by using the following formula:

$$
\alpha-\text { Glucosidase inhibitory activity (\%) }=\left(1-\frac{\mathrm{As}}{\mathrm{Ac}}\right) \times 100
$$

where As and Ac are absorbance of sample and absorbance of control respectively. The control sample contains the enzyme and substrate alone; while the inhibitor solutions were replaced with double distilled water. The concentrations of the peptides resulting in 50\% inhibition of enzyme activity ( $\mathrm{IC}_{50}$ values) were determined using the straight-line equations of the percentage inhibitory activity against the respective logarithm of peptide concentrations [14].

\subsection{Assay for $\alpha$-amylase inhibitory activity of the peptides}

The $\alpha$-amylase inhibitory activity was assayed according to a previously described method [13] with slight modifications. Briefly, $50 \mu \mathrm{L}$ of each peptide or acarbose at a final concentration range of $15.63-500 \mu \mathrm{M}$ was incubated with $25 \mu \mathrm{L}$ of pancreatic amylase (2 $\mathrm{U} / \mathrm{mL}$ ) in $100 \mathrm{mM}$ sodium phosphate buffer $(\mathrm{pH} 6.8)$ at $37^{\circ} \mathrm{C}$ for $60 \mathrm{~min}$. Thereafter, a volume of $25 \mu \mathrm{L}$ of $1 \mathrm{~g} / 100 \mathrm{~mL}$ starch dissolved in $100 \mathrm{mM}$ sodium phosphate buffer $(\mathrm{pH}$ 6.8) was added to the reaction mixture and incubated at $37{ }^{\circ} \mathrm{C}$ for $60 \mathrm{~min}$. This was followed by the addition of $100 \mu \mathrm{L}$ of DNS color reagent and incubated in boiling water for $10 \mathrm{~min}$. The absorbance of the resulting mixture was measured at $540 \mathrm{~nm}$ using a Spectramax paradigm multi-mode microplate reader (Molecular Devices LLC, USA) and the inhibitory activity expressed as percentage of a control sample without the inhibitors. The $\alpha$-amylase inhibitory activity of the peptides was calculated by using the following formula: 
$\alpha-$ Amylase inhibitory activity $(\%)=\left(1-\frac{\mathrm{As}}{\mathrm{Ac}}\right) \times 100$

where As and Ac are absorbance of sample and absorbance of control respectively. The control sample contains the enzyme and substrate alone; while the inhibitor solutions were replaced with double distilled water. The concentrations of the peptides resulting in 50\% inhibition of enzyme activity ( $\mathrm{IC}_{50}$ values) were determined using the straight-line equations of the percentage inhibitory activity against the respective logarithm of peptide concentrations [14].

\subsection{Mechanism of $\alpha$-glucosidase and $\alpha$-amylase inhibitions}

The peptides were subjected to enzyme inhibition kinetic experiments to determine the type of inhibition exerted on $\alpha$-glucosidase and $\alpha$-amylase. The experiment was conducted according to the earlier described protocols [13] at two fixed concentrations of the peptides (250 and $500 \mu \mathrm{M})$ with a variable concentration of substrate. For the $\alpha$-glucosidase and $\alpha$-amylase inhibition assays, 0.15-5 mM of $p$ NPG and 0.125 - $1 \mathrm{~g} / 100 \mathrm{~mL}$ of starch were used, respectively. The initial velocity data obtained were used to construct Lineweaver-Burk plots to determine the $\mathrm{K}_{\mathrm{M}}$ (Michaelis constant), $\mathrm{V}_{\max }$ (maximum velocity) of the enzymes as well as the $K_{\mathrm{i}}$ (inhibition binding constant) of the inhibitors and the type of inhibition for each enzyme.

\subsection{Statistical analysis}

Values are presented as mean \pm SD of two independent experiments done in triplicates and the data were analyzed by using a statistical software package (SPSS for Windows, version 18, IBM Corporation, NY, USA) using Tukey's-HSD multiple range post-hoc test. Values were considered significantly different at $p<0.05$.

\section{Results}

Using the identified structural properties for $\alpha$-glucosidase inhibitory peptides, a library of 4210 peptides was generated comprising of 10 tripeptides, 200 tetrapeptides and 4000 pentapeptides (Table 1). Subsequently, all the peptides were subjected to in silico digestion using a combination of pepsin, chymotrypsin and trypsin in the BIOPEP database. A total of 844 peptides composed of 4 tripeptides, 56 tetrapeptides and 784 pentapeptides were found to be resistant to GIT digestion. Generally, peptides with phenylalanine, lysine, leucine, arginine, 
tryptophan and tyrosine at any position except the ultimate C-terminal end were hydrolyzed. Full details of the in silico digestion for all the 4210 peptides are provided in supplementary Table S1-S12.

Upon confirming their GIT stability, the 844 peptides were subjected to molecular docking analysis to determine the binding free energies toward $\alpha$-glucosidase. The docking analysis revealed that all the stable tripeptides (SPA, SPM, TPA and TPM) had binding free energies of < $-7.0 \mathrm{kcal} / \mathrm{mol}$, while the standard drug, acarbose had a binding free energy of $-7.0 \mathrm{kcal} / \mathrm{mol}$ (Table 2). The 56 stable tetrapeptides had binding free energies in the range of -5.8 to -8.7 $\mathrm{kcal} / \mathrm{mol}$, with SVPA and SEPA having the lowest binding free energy values of -8.7 and -8.6 $\mathrm{kcal} / \mathrm{mol}$, respectively. The data for the binding energy values of the stable 784 pentapeptides are not shown due to space constraints. However, it is noteworthy that, of these 784 pentapeptides, TPPPA, TAGPA, TAQPA, TGAPA, SPEPM, TGEPA had the lowest binding free energy values of $-8.4,-8.2,-8.2,-8.1,-8.0$, and $-8.0 \mathrm{kcal} / \mathrm{mol}$ respectively. Molecular docking also revealed that for all the stable 844 peptides, peptides with alanine at the ultimate $\mathrm{C}$-terminal residue had lower binding free energy values than their counterparts with methionine at the $\mathrm{C}$-terminal residue.

Table 2. Binding free energy values of tri- and tetrapeptides with potential $\alpha$-glucosidase inhibitory activity and resistant to in silico simulated gastrointestinal digestion*

\begin{tabular}{cccc}
\hline Tripeptide & $\begin{array}{c}\text { Binding free } \\
\text { energy value } \\
(\mathrm{kcal} / \mathrm{mol})\end{array}$ & Tetrapeptide & $\begin{array}{c}\text { Binding free } \\
\text { energy value } \\
(\mathrm{kcal} / \mathrm{mol})\end{array}$ \\
\hline SPA & -6.7 & SAPA & -6.9 \\
& & SCPA & -7.5 \\
& SDPA & -7.9 \\
& SEPA & $-\mathbf{8 . 6}$ \\
& SGPA & -7.1 \\
& SHPA & -6.8 \\
& SIPA & -6.6 \\
& SMPA & -7.1 \\
& & SNPA & -7.0 \\
& & SPPA & -6.4 \\
& & SQPA & -7.1 \\
& & SSPA & -6.7 \\
& & STPA & -6.6 \\
& & SVPA & -8.7 \\
& & SAPM & -7.0 \\
& -6.0 & SCPM & -6.4 \\
& & SDPM & -5.8 \\
& & SEPM & -6.8 \\
& & & 9
\end{tabular}




\begin{tabular}{|c|c|c|c|}
\hline & & SGPM & -6.5 \\
\hline & & SHPM & -6.8 \\
\hline & & SIPM & -6.4 \\
\hline & & SMPM & -6.1 \\
\hline & & SNPM & -6.4 \\
\hline & & SPPM & -6.6 \\
\hline & & SQPM & -6.6 \\
\hline & & SSPM & -7.0 \\
\hline & & STPM & -6.4 \\
\hline & & SVPM & -5.9 \\
\hline \multirow{14}{*}{ TPA } & -6.5 & TAPA & -7.4 \\
\hline & & TCPA & -6.9 \\
\hline & & TDPA & -7.6 \\
\hline & & TEPA & -7 \\
\hline & & TGPA & -7.6 \\
\hline & & THPA & -7.7 \\
\hline & & TIPA & -7.6 \\
\hline & & TMPA & -6.3 \\
\hline & & TNPA & -6.9 \\
\hline & & TPPA & -7.3 \\
\hline & & TQPA & -6.8 \\
\hline & & TSPA & -7.1 \\
\hline & & TTPA & -7.2 \\
\hline & & TVPA & -7.1 \\
\hline \multirow[t]{14}{*}{ TPM } & -6.3 & TAPM & -6.2 \\
\hline & & TCPM & -6.5 \\
\hline & & TDPM & -6.6 \\
\hline & & TEPM & -6.5 \\
\hline & & TGPM & -6.5 \\
\hline & & THPM & -6.5 \\
\hline & & TIPM & -7.1 \\
\hline & & TMPM & -6.1 \\
\hline & & TNPA & -6.5 \\
\hline & & TPPM & -6.9 \\
\hline & & TQPM & -6.6 \\
\hline & & TSPM & -6.9 \\
\hline & & TTPM & -6.8 \\
\hline & & TVPM & -6.3 \\
\hline $\begin{array}{l}\text { Acarbose } \\
\text { (known } \\
\text { nhibitor) }\end{array}$ & -7.0 & - & - \\
\hline
\end{tabular}

*Simulated gastrointestinal digestion was conducted with a combination of chymotrypsin, trypsin and pepsin in the BIOPEP database (http://www.uwm.edu.pl/biochemia/index.php/en/biopep)

The bolded peptide sequences had the lowest binding free energy values 

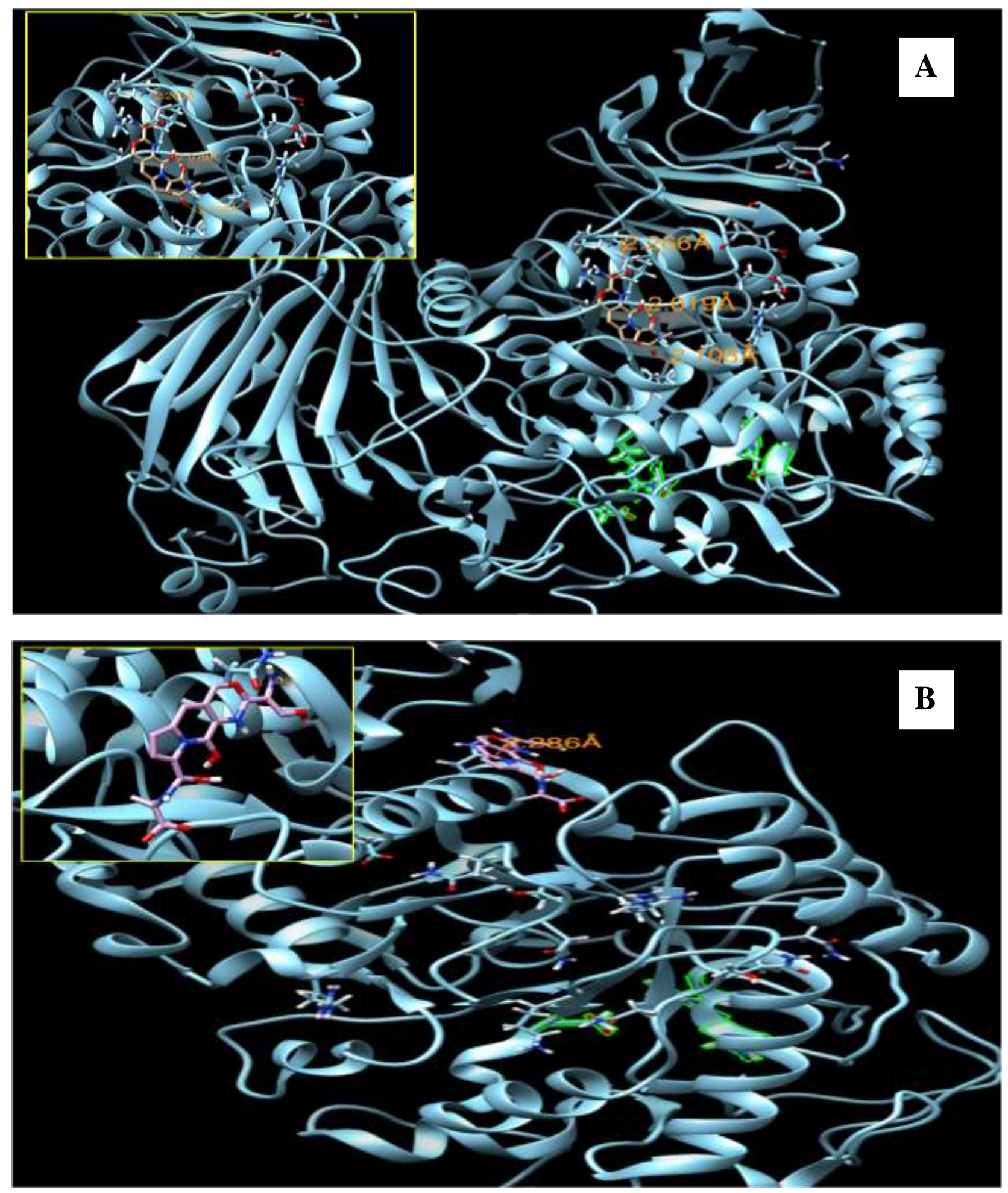

Fig 1. The mode of interaction between SVPA with the N-terminal domain of human $\alpha$-glucosidase (A) and human pancreatic $\alpha$-amylase $(\mathbf{B})$. The orange lines represent the hydrogen bonds with the respective bond distance (also provided in Table 3), while the active site residues are indicated in green. The binding site has been zoomed out for each peptide- $\alpha$-glucosidase interaction and presented at top left side of the respective interaction. 
The lowest binding free energies of SVPA and SEPA prompted further investigation of the docking pose and hydrogen bonding interactions between these peptides and $\alpha$-glucosidase. The SVPA was found to interact with the enzyme at a site distant from the active site with 3 hydrogen bond interactions and bond distances that ranged between $2.019 \AA$ A to $2.266 \AA$ (Fig. 1). These interactions are mainly mediated by the S1, P3 and A4 of the peptide while the important binding site residues on the enzyme involved in the hydrogen bond interactions are L286, I523 and V779 (Table 3). $\alpha$-Glucosidase inhibition is associated with the inhibition of $\alpha$-amylase activity and therefore, the potential of the peptide to inhibit $\alpha$-amylase was initially investigated using the molecular docking. Interestingly, SVPA was found to also interact with the human $\alpha$ amylase at a site distant from the active site (Figure 1) with a binding free energy of -6.5 $\mathrm{kcal} / \mathrm{mol}$ (Table 3) and a single hydrogen bond between S1 of the peptide ligand and N393 of the human $\alpha$-amylase (Table 3).

Table 3. Molecular docking results and binding free energy $(\mathrm{kcal} / \mathrm{mol})$ of SVPA with the N-terminal domain of human $\alpha$-glucosidase and human pancreatic $\alpha$-amylase

\begin{tabular}{lcclll}
\hline Enzyme & $\begin{array}{l}\text { Binding } \\
\text { energy } \\
(\mathrm{kcal} / \mathrm{mol})\end{array}$ & $\begin{array}{l}\text { Number of } \\
\text { hydrogen } \\
\text { bonds }\end{array}$ & $\begin{array}{l}\text { Interacting } \\
\text { residue of the } \\
\text { peptide }\end{array}$ & $\begin{array}{l}\text { Interacting } \\
\text { residue of the } \\
\alpha \text {-glucosidase }\end{array}$ & $\begin{array}{l}\text { Hydrogen } \\
\text { bond distance } \\
(\AA)\end{array}$ \\
\hline$\alpha$-Glucosidase & -8.7 & 3 & $\mathrm{P} 3(\mathrm{C}=\mathrm{O})$ & $\mathrm{L} 286(\mathrm{~N}-\mathrm{H})$ & 2.019 \\
& & & $\mathrm{~A} 4(\mathrm{C}=\mathrm{O})$ & $\mathrm{I} 523(\mathrm{~N}-\mathrm{H})$ & 2.108 \\
& & $\mathrm{~S} 1(\mathrm{OH})$ & $\mathrm{V} 779(\mathrm{~N}-\mathrm{H})$ & 2.266 \\
$\alpha$-Amylase & -6.5 & 1 & $\mathrm{~S} 1\left(\mathrm{NH}_{2}\right)$ & $\mathrm{N} 393(\mathrm{C}=\mathrm{O})$ & 2.286
\end{tabular}

The functional groups involved in the hydrogen bond formation are indicated in parenthesis next to the respective amino acid residues. $\mathrm{N}-\mathrm{H}$ refers to the amino group involved in the peptide bond while $\mathrm{NH}_{2}$ refers to the free amino group at the N-terminal of the peptide

SEPA interacted at a close proximity to the active site of $\alpha$-glucosidase with 5 hydrogen bond interactions and bond distances between $1.847 \AA$ to $2.576 \AA$ (Fig. 2). These interactions occurred between S1, E2, P3 and A4 of the peptide and R202, R526 and H600 of the enzyme (Table 4). In contrast, SEPA interacted with human $\alpha$-amylase at a site other than the active site (Figure 2) with a binding free energy value of $-6.9 \mathrm{kcal} / \mathrm{mol}$ and 3 hydrogen bonds between $\mathrm{S} 1, \mathrm{P} 3$ and A4 of the peptide and P332, R252 and S3 of human $\alpha$-amylase (Table 4). 

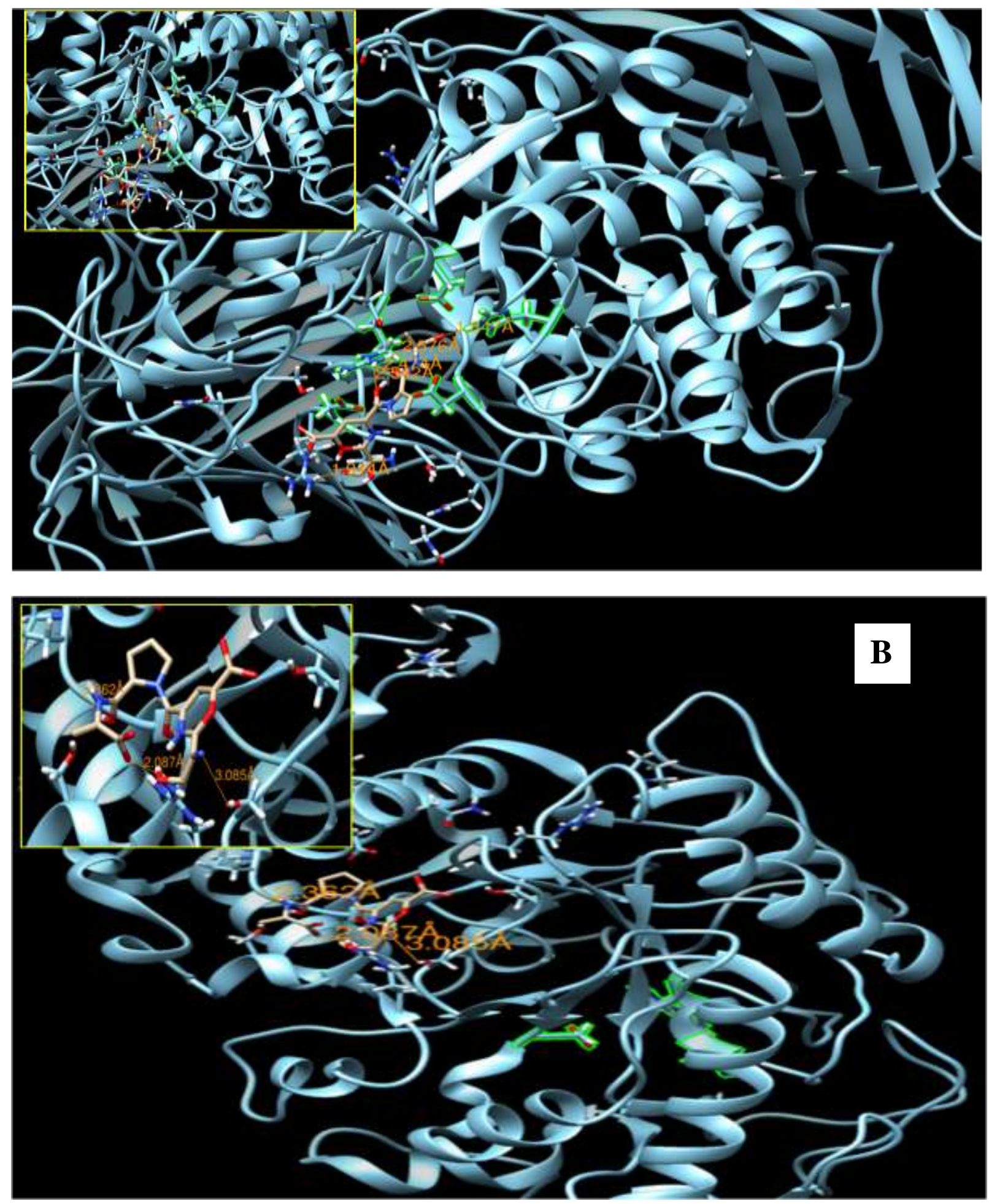

Fig. 2. The mode of interaction between SEPA with the N-terminal domain of human $\alpha$-glucosidase (A) and human pancreatic $\alpha$-amylase (B). The orange lines represent hydrogen bonds with the respective bond distance (also provided in Table 4), while the active site residues are indicated in green. The binding site has been zoomed out for each peptide- $\alpha$-glucosidase interaction and presented at top left side of the respective interaction. 
Table 4. Docking results and binding free energy ( $\mathrm{kcal} / \mathrm{mol})$ of SEPA with the N-terminal domain of human $\alpha$-glucosidase and human pancreatic $\alpha$-amylase

\begin{tabular}{|c|c|c|c|c|c|}
\hline Enzyme & $\begin{array}{l}\text { Binding } \\
\text { energy } \\
(\mathrm{kcal} / \mathrm{mol})\end{array}$ & $\begin{array}{l}\text { Number of } \\
\text { hydrogen } \\
\text { bonds }\end{array}$ & $\begin{array}{l}\text { Interacting } \\
\text { residue of the } \\
\text { peptide }\end{array}$ & $\begin{array}{l}\text { Interacting } \\
\text { residue of the } \\
\alpha \text {-amylase }\end{array}$ & $\begin{array}{l}\text { Hydrogen } \\
\text { bond distance } \\
(\AA)\end{array}$ \\
\hline \multirow[t]{5}{*}{$\alpha$-Glucosidase } & -8.6 & 5 & $\mathrm{~S} 1(\mathrm{OH})$ & $\mathrm{R} 202\left(* \mathrm{NH}_{2}\right)$ & 1.914 \\
\hline & & & $\mathrm{E} 2(\mathrm{C}=\mathrm{O})$ & R526 (NH1) & 2.542 \\
\hline & & & $\mathrm{P} 3(\mathrm{C}=\mathrm{O})$ & R526 (NH1) & 2.474 \\
\hline & & & $\mathrm{A} 4\left(\mathrm{O}^{-}\right)$ & R526 (NH) & 2.576 \\
\hline & & & $\mathrm{A} 4(\mathrm{C}=\mathrm{O})$ & H600 (-N=) & 1.847 \\
\hline \multirow[t]{3}{*}{$\alpha$-Amylase } & -6.9 & 3 & $\mathrm{P} 3(\mathrm{C}=\mathrm{O})$ & P332\# & 2.362 \\
\hline & & & $\mathrm{A} 4(\mathrm{C}=\mathrm{O})$ & $\mathrm{R} 252\left(* \mathrm{NH}_{2}\right)$ & 2.087 \\
\hline & & & $\mathrm{S} 1\left(\mathrm{NH}_{2}\right)$ & $\mathrm{S} 3(\mathrm{OH})$ & 3.085 \\
\hline
\end{tabular}

The functional groups involved in the hydrogen bond formation are indicated in parenthesis next to the respective amino acid residues. $\mathrm{NH}_{2}$ refers to the free amino group at the $\mathrm{N}$-terminal of the peptide while $* \mathrm{NH}_{2}$ and $\mathrm{NH} 1$ refer to the amino and imino groups on the side chain of arginine, respectively.

\#The H-donor of P332 could not be predicted by the software

Having established the potential of SVPA and SEPA as $\alpha$-glucosidase and $\alpha$-amylase inhibitors using in silico analysis, the synthetic peptides were investigated for in vitro $\alpha$ glucosidase and $\alpha$-amylase inhibitory activities. Both peptides were found to inhibit both $\alpha$ glucosidase and $\alpha$-amylase activities in vitro. In comparison to acarbose, only SEPA displayed significantly $(\mathrm{p}<0.05)$ lower $\mathrm{IC}_{50}$ values for $\alpha$-glucosidase $\left(\mathrm{IC}_{50}=0.79 \pm 0.16 \mathrm{mM}\right)$ and $\alpha$ amylase $\left(\mathrm{IC}_{50}=2.09 \pm 0.20 \mathrm{mM}\right)$ inhibitory activities. This peptide is therefore approximately 2.2 and 90.9 times a more potent inhibitor of $\alpha$-glucosidase and $\alpha$-amylase inhibitions, respectively, than acarbose (Table 5). However, SVPA had a significantly lower $(p<0.05) \mathrm{IC}_{50}$ value $(5.92 \pm 2.6 \mathrm{mM})$ than acarbose and was 32.1 times more active. For $\alpha$-glucosidase inhibition, SVPA was 2.7 times less active compared with acarbose. The ratio of $\mathrm{IC}_{50}$ values for inhibiting $\alpha$-glucosidase and $\alpha$-amylase was in the order acarbose $<$ SEPA $<$ SVPA (Table 5). 
Table 5. $\mathrm{IC}_{50}$ values for $\alpha$-glucosidase and $\alpha$-amylase inhibition by SVPA, SEPA and acarbose

Peptide/Control

$$
\mathrm{IC}_{50}(\mathrm{mM})
$$

$$
\alpha \text {-Glucosidase }
$$

\section{Ratio of $\mathrm{IC}_{50}$} values of $\alpha-$ glucosidase to $\alpha-$ amylase inhibition

$\begin{array}{cccc}\text { SVPA } & 4.56 \pm 1.56^{\mathrm{c}} & 5.92 \pm 2.6^{\mathrm{a}} & 1: 1.29 \\ \text { SEPA } & 0.79 \pm 0.16^{\mathrm{a}} & 2.09 \pm 0.20^{\mathrm{a}} & 1: 2.64 \\ \text { Acarbose } & 1.72 \pm 0.65^{\mathrm{b}} & 190.05 \pm 19.95^{\mathrm{b}} & 1: 110.49\end{array}$

Data are expressed as mean \pm SD of two independent experiments done in triplicate. ${ }^{a-b}$ Values with different subscript letters along a column are significantly different from each other (Tukey's-HSD multiple range post hoc test, $\mathrm{p}<0.05$ )

The enzyme kinetic studies revealed that SVPA is an uncompetitive inhibitor of both $\alpha$ glucosidase and $\alpha$-amylase (Fig. 3), thereby decreasing both Vmax and $\mathrm{K}_{M}$ of the enzymes. The computed inhibition binding constants (Ki) of SVPA were 1.38 and $4.30 \mathrm{mM}$ for $\alpha$-glucosidase and $\alpha$-amylase, respectively. In contrast, SEPA was determined to be a non-competitive inhibitor of $\alpha$-glucosidase (Fig. 4A) with Vmax decreasing while the $\mathrm{K}_{\mathrm{M}}$ remained unchanged at 2.85 $\mathrm{mM}$. However, for $\alpha$-amylase, an uncompetitive inhibition pattern was observed (Fig. 4B). The $\mathrm{Ki}$ of SEPA for $\alpha$-glucosidase and $\alpha$-amylase inhibitions was 2.42 and $6.50 \mathrm{mM}$ respectively. 

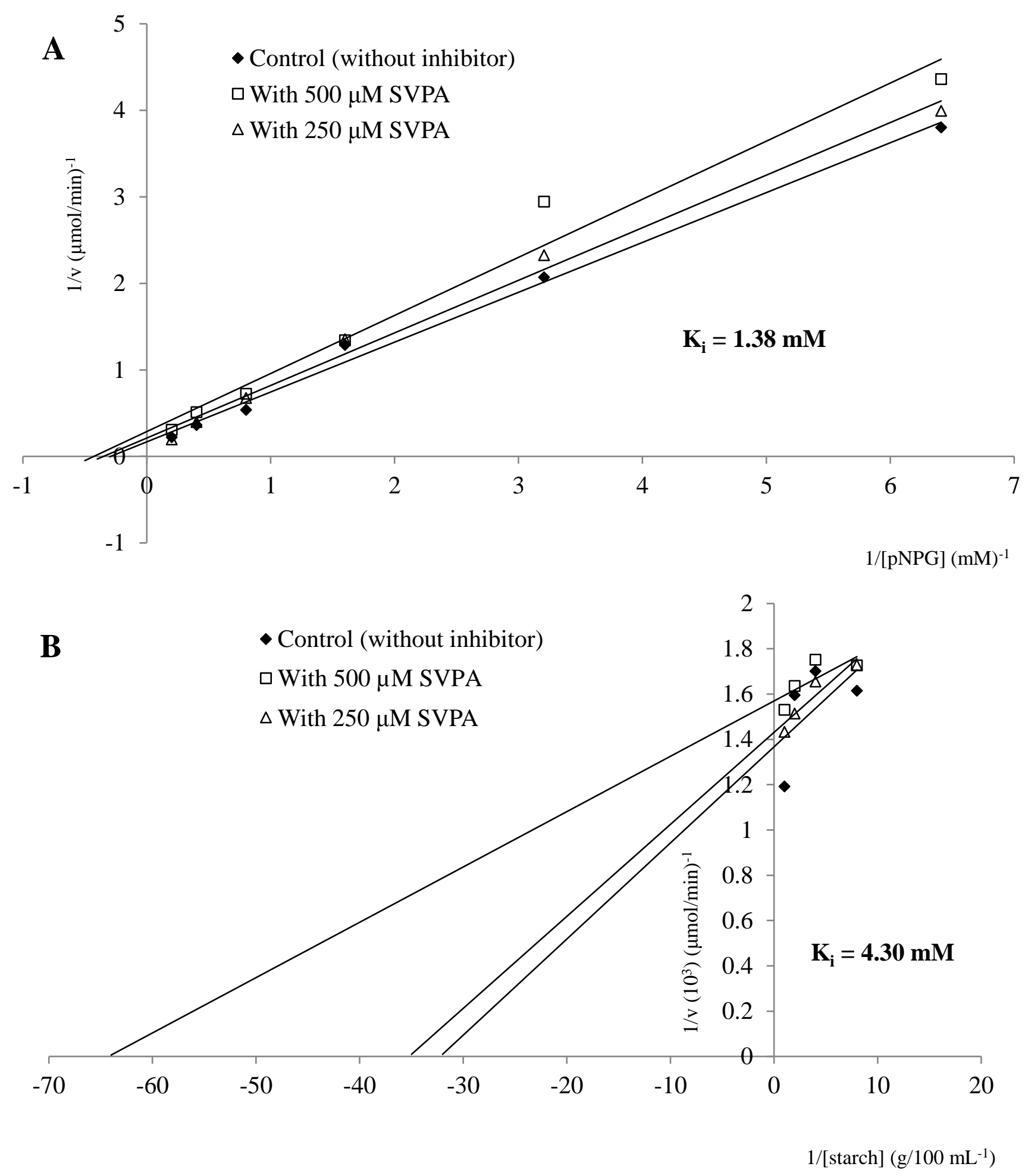

Fig. 3. Lineweaver-Burk plots of $\alpha$-glucosidase (A) and $\alpha$-amylase (B) catalysed reactions in the presence of SVPA. Each data point represents a mean of two independent experiments done in triplicates 

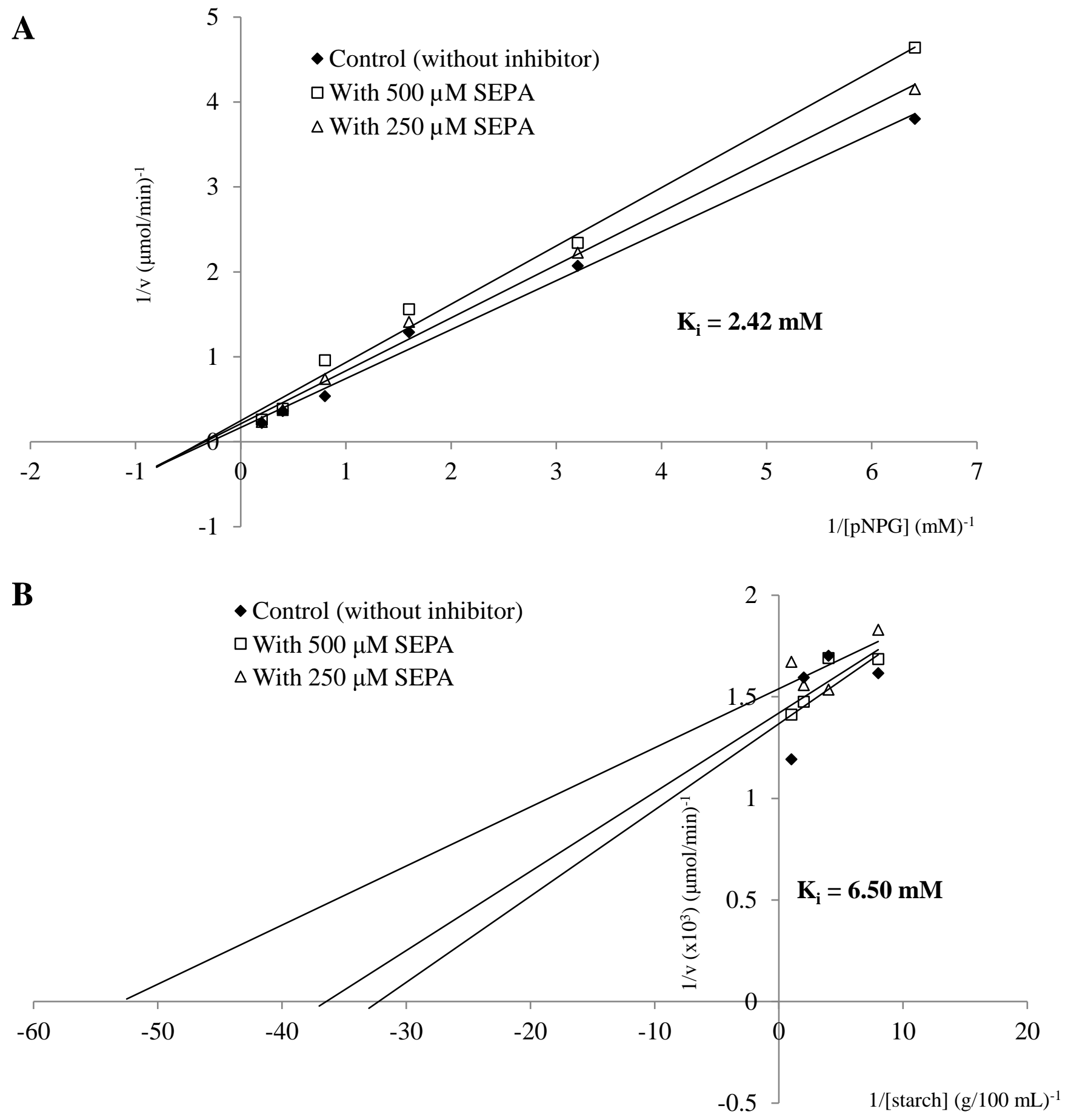

Fig. 4. Lineweaver-Burk plots of $\alpha$-glucosidase (A) and $\alpha$-amylase (B) catalysed reactions in the presence of SEPA. Each data point represents a mean of two independent experiments done in triplicates 


\section{Discussion}

The search for novel $\alpha$-glucosidase inhibitory peptides is of utmost interest for the food and biopharmaceutical industries. This is because these peptides have the potential to serve as possible components of nutraceuticals or biopharmaceuticals and as chemotherapeutic agents, that could reduce diabetes-related health burdens in addition to improved economic benefits to the industries. In this study, an in silico strategy was used to design 844 GIT stable $\alpha$-glucosidase inhibitory peptides from which two novel and promising candidates were selected for validation using in vitro methods.

A library of 4210 potential $\alpha$-glucosidase inhibitory peptides was designed including tripeptides, tetrapeptides and pentapeptides. However, for practical therapeutic application, the $\alpha$-glucosidase inhibitory peptides have to reach the intestinal lumen in an intact form to bind the $\alpha$-glucosidase at the small intestinal mucosa. Therefore, the 4210 peptides were subjected to in silico simulated digestion in the BIOPEP database [15] and only 844 peptides were resistant to GIT digestion. The remaining peptides were prone to the GIT digestion and were observed to mainly contain amino acids; phenylalanine, lysine, leucine, arginine, tryptophan and tyrosine at all positions except the $\mathrm{C}$-terminal end. This observation might suggest that future design of any bioactive peptide for oral application, not even necessarily $\alpha$-glucosidase inhibitory peptides, should avoid the inclusion of these amino acids except at the ultimate C-terminal position.

Molecular docking is now a routine and rapid high throughput tool used in virtual drug screening and design [16]. All 844 stable peptides were subjected to molecular docking analysis to determine their binding free energies with the $\alpha$-glucosidase. Interestingly, all the peptides had affinity towards $\alpha$-glucosidase with the binding affinity for most of the peptides better than acarbose suggesting that they may possess $\alpha$-glucosidase inhibitory effects. Evaluation of the binding free energy values showed that the tripeptides generally demonstrated poor binding affinity towards $\alpha$-glucosidase, when compared to the tetrapeptides and pentapeptides. This is unlike the case of dipeptidyl peptidase IV peptide inhibitors where tripeptides had better binding affinity than peptides with a higher number of amino acids [17]. This suggests that the development of optimum multifunctional antidiabetic peptides that target both enzyme systems might require rigorous optimization to be successful. It was noted that peptides with sulphur- 
containing amino acids (cysteine and methionine) generally had relatively higher binding free energies than their counterparts without these amino-acids indicating that the presence of sulphur weakens the binding affinity of $\alpha$-glucosidase inhibitory peptides. Of the 844 GIT stable peptides subjected to the molecular docking, the tetrapeptides SVPA and SEPA had the highest binding affinity and were therefore selected for a more detailed molecular docking studies and in vitro evaluation.

The active site of the intestinal human $\alpha$-glucosidase used in this study comprises of R526, D542, H600, D327 and D203 [18] but none of these amino acids interacted with SVPA suggesting a non-competitive-like type of interaction. However, of the 5 hydrogen bonds between SEPA and $\alpha$-glucosidase, 3 bonds were formed with R526 and 1 bond with H600 which are among the active site residues and the remaining hydrogen bond was with R202 which is close to D203 in the active site. The foregoing observations clearly demonstrated a competitive type of interaction between SEPA and $\alpha$-glucosidase, whilst the R526 might be a critical amino acid for the trapping of the $\alpha$-glucosidase inhibitory peptides. This result is similar to the competitive-like type of interaction shown by acarbose (data not shown). However, in the peptide ligands, the 3 common amino acids of both peptides (S1, P3 and A4) and E2 ( SEPA) were found to be mainly responsible for the hydrogen bond interactions suggesting that the valine residue might be responsible for preventing SVPA from binding at the active site and thereby making it a non-competitive type of inhibitor. Overall, the presence of serine at the Nterminal position of the $\alpha$-glucosidase inhibitory peptides could be linked to the side chain hydroxyl group which forms hydrogen bond interaction with the $\alpha$-glucosidase protein. The presence of proline in the peptide ligands might have affected the flexibility of the peptides and consequently increase their binding affinity towards the $\alpha$-glucosidase. Moreover, the presence of proline at the C-terminal region is a common feature of potent peptide inhibitors [19] and has also been reported to protect peptides from proteolysis [20].

An important feature of $\alpha$-glucosidase inhibitors is also to mildly inhibit $\alpha$-amylase activity because the latter catalyses the initial step of starch digestion that yields disaccharides as substrates for the $\alpha$-glucosidase [6]. In fact, we previously observed that the failure to investigate the corresponding $\alpha$-amylase inhibitory activity of most of the investigated $\alpha$-glucosidase inhibitory peptides was a major limitation in the search for novel $\alpha$-glucosidase inhibitory 
peptides. This is an area that deserves utmost research attention if pharmaceutically relevant $\alpha$ glucosidase inhibitory peptides are to be developed [11]. Therefore, SVPA and SEPA were also investigated for $\alpha$-amylase inhibitory activity but they were initially subjected to the molecular docking analysis to determine their binding potential towards the enzyme. It was interesting to note that both peptides bind to the enzyme with SEPA having a better binding affinity but both peptides acted in a non competitive-like manner as none of the active site residues of the $\alpha$ amylase; Q63, W59 and D197 were involved in the interaction [21].

In vitro analysis of the $\alpha$-glucosidase and $\alpha$-amylase inhibitory activities of the synthetic SVPA and SEPA also indicated that both peptides are inhibitors of the two enzymes and consequently have the ability to retard the breakdown of dietary carbohydrates and reduce glucose absorption from the small intestine [22]. Consequently, the uptake of glucose into the bloodstream will be lowered, thereby controlling postprandial hyperglycemia [23]. However, compared to acarbose and SVPA, SEPA had better inhibitory activities against both enzymes and is also clearly better than 27 out of the 43 (based on $\mathrm{IC}_{50}$ values) previously reported $\alpha$ glucosidase inhibitory peptides [11]. Some of the side effects of the currently available $\alpha$ glucosidase inhibitors are linked to excessive inhibition of $\alpha$-amylase activity [24]. Hence, the ratio of $\mathrm{IC}_{50}$ values for $\alpha$-glucosidase to $\alpha$-amylase inhibition was determined. The findings suggest that SEPA is a more potent inhibitor of $\alpha$-glucosidase than $\alpha$-amylase $(1: 2.6)$ which is a desirable feature for drug candidates to be used as potential $\alpha$-glucosidase inhibitors by biopharmaceutical industries. In this regard, it is also noteworthy that acarbose with a ratio of 1:110.49 had a milder inhibition of $\alpha$-amylase than SEPA suggesting that minor structural adjustment might be needed on SEPA to produce a weaker inhibitor of $\alpha$-amylase.

The observation of a higher enzymes inhibitory activity of SEPA in the in vitro studies is not in agreement with the molecular docking analysis where SVPA was found to have higher binding affinity than SEPA. This is not surprising considering the fact that molecular docking analysis does not always correlate with in vitro experiments [16]. Indeed, this is more evident when the inhibition kinetics data is considered where none of the molecular docking analysis versus in vitro experiments quite corresponded. For SVPA, both enzymes were inhibited uncompetitively in the in vitro studies and non-competitively in the molecular docking analyses, while SEPA revealed a non-competitive inhibition in vitro and a competitive inhibition in the 
molecular docking against $\alpha$-glucosidase. Also, acarbose, a known competitive inhibitor of $\alpha$ glucosidase was confirmed to exhibit competitive inhibition in the present study with molecular docking analysis but a number of in vitro experiments have also shown that acarbose is a mixed inhibitor $[25,26]$. These observations demonstrate the need to further validate some of the docking data with in vitro experiments. In spite of these differences, it is still possible to suggest, based on the in vitro data, that SVPA and SEPA are capable of interacting with $\alpha$-glucosidasepNPG and $\alpha$-amylase-starch complexes and consequently reducing the $\alpha$-glucosidase and $\alpha$ amylase activities, respectively [27].

In conclusion, we have used in silico and in vitro analyses to design two novel $\alpha$ glucosidase and $\alpha$-amylase inhibitory peptides, SVPA and SEPA that could have the potential to retard postprandial hyperglycemia in diabetic patients. To date, these peptides have not been identified in natural sources. The in vivo investigation of the GIT stability, the antidiabetic effects, bioavailability and toxicity profile of the peptides would be the subject of further studies with the ultimate aim of developing these peptides as either supplements or antidiabetic drugs. These preclinical studies would be the next step along the drug discovery and development pipeline which would provide conclusive evidence on the pharmaceutical relevance and potential application of these novel peptides in the management of T2D.

\section{Acknowledgement}

We acknowledge the National Research Foundation of South Africa and the University of Pretoria for the financial support. The first author also acknowledges the University of Pretoria for the award of a postdoctoral fellowship position in Biochemistry and Ahmadu Bello University, Zaria, Nigeria for the award of a study fellowship.

\section{References}

[1] D.R. Whiting, L. Guariguatga, C. Weil, J. Shaw, IDF Diabetes Atlas: Global estimates of the prevalence of diabetes for 2011 and 2030, Diabetes Res. Clin. Pract. 94 (3) (2011) $311-321$.

[2] International Diabetes Federation. IDF Diabetes Atlas, (2015). 7th ed., (www.idf.org) 
[3] E.J. Wright, J.L. Scism-Bacon, L.C. Glass, Oxidative stress in type 2 diabetes: the role of fasting and postprandial glycaemia, Int. J. Clin. Pract. 60 (3) (2006) 308-314.

[4] A.A. Tahrani, C.J. Bailey, S. Del Prato, A.H. Barnett, Management of type 2 diabetes: new and future development, Lancet. 378 (2011) 182-197.

[5] B. Konrad, A. Dabrowski, M. Szoltysik, P. Marta, Z. Aleksandra, C. Jozefa, The evaluation of dipeptidyl peptidase (DPP)-IV, $\alpha$-glucosidase and angiotensin converting enzyme (ACE) inhibitory activities of whey proteins hydrolysed with serine protease isolated from Asian pumpkin (Cucurbita ficifolia), Int. J. Pept. Res. Ther. 20 (2014) 483491.

[6] S. Ponnusamy, S. Haldar, F. Mulani, S. Zinjarde, H. Thulasiram, A. RaviKumar, Gedunin and azadiradione: human pancreatic alpha-amylase inhibiting limonoids from neem (Azadirachta indica) as anti-diabetic agents, PLoS One 10 (10) (2015) e0140113.

[7] Z. Yu, Y. Yin, W. Zhao, Y. Yu, B. Liu, J. Liu, F. Chen, Novel peptides derived from egg white protein inhibiting alpha-glucosidase, Food Chem. 129 (4) (2011) 1376-1382.

[8] N. S. Moorthy, M. J. Ramos, P. A. Fernandes, Studies on alpha glucosidase inhibitors development: magic molecules for the treatment of carbohydrate mediated diseases, Mini Rev. Med. Chem. 12 (2012) 713-720.

[9] P. Patil, S. Mandal, S. K. Tomar, S. Anand, Food protein-derived bioactive peptides in management of type 2 diabetes, Eur. J. Nutr. 54 (2015) 863-880.

[10] I. Roskar, P. Molek, M. Vodnik, M. Stempelj, B. Strukelj, M. Lunder, Peptides modulators of alpha-glucosidase, J. Diabetes Inv. 6 (2015) 625-631. 
[11] M. A. Ibrahim, M. J. Bester, A. W. H. Neitz, A. R. M. Gaspar, Structural properties of bioactive peptides with $\alpha$-glucosidase inhibitory activity, Chem. Biol. Drug Des. (2017) DOI: 10.1111/cbdd.13105

[12] O. Trott, A. J. Olson, AutoDock Vina: improving the speed and accuracy of docking with a new scoring function, efficient optimization and multithreading, J. Comput. Chem. 31 (2010) 455-461.

[13] M. A. Ibrahim, N. Koorbanally, M. S. Islam, Anti-oxidative activity and inhibition of key enzymes linked to type 2 diabetes ( $\alpha$-glucosidase and $\alpha$-amylase) by Khaya senegalensis, Acta Pharm. 64 (2014) 311-324.

[14] L. J. Shai, P. Masoko, M. P. Mokgotho, S. P. Magano, A. M. Mogale, N. Boaduo, J. N. Eloff, Yeast alpha glucosidase inhibitory and antioxidant activities of six medicinal plants collected in Phalaborwa, South Africa, South Afr. J. Bot. 76 (2010) 465-470.

[15] P. Minkiewicz, J. Dziuba, A. Iwaniak, M. Dziuba, M. Darewicz, BIOPEP database and other programs for processing bioactive peptide sequences, J. AOAC Int. 91 (2008) 965.

[16] C. Y. Chen, Beware of docking!, Trends Pharmacol. Sci. 36 (2) (2015) 78-95.

[17] A. B. Nongonierma, C. Mooney, D. C. Shields, R. J. FitzGerald, In silico approaches to predict the potential of milk protein-derived peptides as dipeptidyl peptidase IV (DPPIV) inhibitors, Peptides. 57 (2014) 43-51.

[18] L. Sim, K. Jayakanthan, S. Mohan, R. Nasi, B. D. Johnston, B. M. Pinto, D. R. Rose, New glucosidase inhibitors from an ayurvedic herbal treatment for type 2 diabetes: structures and inhibition of human intestinal maltase-glucoamylase with compounds from Salacia reticulata, Biochemistry. 49 (2010) 443-451.

[19] H. S. Cheung, F. L. Wang, M. A. Ondetti, E. F. Sabo, D. W. Cushma, Binding of peptide substrate and inhibitors of angiotensin converting enzyme, J. Biol. Chem. 255 (1980) $401-407$. 
[20] H. Meisel, Multifunctional peptides encrypted in milk proteins, BioFactors. 21 (2004) 55 61.

[21] L. K. Williams, C. Li, S. G. Withers, G. D. Brayer, Order and disorder: differential structural impacts of myricetin and ethyl caffeate on human amylase, an antidiabetic target, J. Med. Chem. 55 (2012) 10177-10186.

[22] Y. I. Kwon, E. Apostolidis, Y. C. Kim, K. Shetty, Health benefits of traditional corn, beans and pumpkin: in vitro studies for hyperglycemia and hypertension management, J. Med. Food 10 (2007) 266-275.

[23] O. Kamiyama, F. Sanae, K. Ikeda, Y. Higashi, Y. Minami, N. Asano, I. Adachi, A. Kato, In vitro inhibition of $\alpha$-glucosidases and glycogen phosphorylase by catechin gallates in green tea, Food Chem. 122 (2010) 1061-1066.

[24] A. J. Krentz, C. J. Bailey, Oral antidiabetic agents: current role in type 2 diabetes mellitus, Drugs. 65 (2005) 385-411.

[25] H. U. Son, S. H. Lee, Comparison of $\alpha$-glucosidase inhibition by Cudrania tricuspidata according to harvesting time, Biomed. Rep. 1 (2013) 624-628.

[26] C. Proença, D. Ribeiro, E. F. T. Oliveira, L. T. C. Sousa, S. M. Tomé, M. J. Ramos, A. M. S. Silva, A. P. Fernandes, E. Fernandes, $\alpha$-Glucosidase inhibition by flavonoids: an in vitro and in silico structure-activity relationship study, J. Enz. Inh. Med. Chem. 32 (1) (2017) 1216-1228.

[27] M. A. Ibrahim, N. Koorbanally, M. S. Islam, Anti-oxidative, $\alpha$-glucosidase and $\alpha$ amylase inhibitory activity of Vitex doniana: possible exploitation in the management of type 2 diabetes. Acta Pol. Pharm. 73 (5) (2016) 1235-1247. 